\title{
LAS MODALIDADES DEL CUENTO ORAL Y LOS NUEVOS NARRADORES
}

\author{
Cristina LAVINIO \\ Università di Cagliari \\ lavinio@unica.it
}

Resumen: La teatralidad verbal de la narración oral tradicional se manifiesta en algunos fenómenos lingüísticos, utilizados aquí para evaluar las performances de los nuevos narradores y su grado de adhesión a las formas orales del contar (ejemplos de Celestini, Enia, Zanotto).

\begin{abstract}
The oral narrative's verbal sense of the theatre becomes obvious in some linguistic phenomena used in this work in order to evaluate the new storytellers' performances, as well as their greater or lesser adherence to the narrative oral forms. I.e. Celestini, Enia, Zanotto.
\end{abstract}

Palabras clave: Oralidad. Narrativa tradicional. Teatro de narración. Rasgos lingüísticos.

Key words: Orality. Traditional narrative. Narrative theatre. Linguistic features. 


\section{PREMISA}

El fenómeno de un gusto renovado por la audición y recepción de la literatura mediante la escucha está cada vez más difundido y tiene dimensiones internacionales.

Por lo que respecta a Italia, basta pensar en el éxito de las lecturas públicas de la obra de Dante, en plazas o iglesias abarrotadas, realizadas por Vittorio Sermonti o Roberto Benigni. Además, se multiplican los festivales literarios, sobre el modelo del de Mantua (una cita anual de éxito extraordinario), en los que se van difundiendo cada vez más, con ocasión de la presentación de nuevas novelas, las lecturas en voz alta de páginas escogidas, realizadas incluso por actores

Puede afirmarse que es el momento de la narrativa, después del de la poesía y de la difusión de las performances de recitación de textos poéticos, que ya señaló Maria Corti (1982), remitiéndose, por otra parte a indicaciones de Northrop Frye con referencia al final de los años sesenta del siglo XX. Hoy el uso de la narración oral en plazas, cafés, teatros es cada vez más amplio ${ }^{1}$, bien se trate de una lectura en voz alta de páginas escritas realizada para la audición colectiva, bien se trate de auténticas performances en las que el texto nace en el ámbito de la oralidad, desarrollando un esquema memorizado, dotado o no de base escrita.

Es posible afirmar que esta nueva difusión de la oralidad y de la necesidad de escuchar se injerta en costumbres culturales vinculadas a la oralidad secundaria (Ong, 1982) a las que, desde hace tiempo, nos han acostumbrado los medios de comunicación — radio y sobre todo televisión-. No obstante, vivimos, además, un momento en el que los géneros y las variedades lingüísticas se mezclan y se confunden como nunca. Asimismo, la narrativa oral se acerca de forma cada vez más indiscutible al teatro, en una lengua que, sin embargo, procede a menudo de una base escrita y conserva huellas más o menos profundas de este hecho; mientras que la escritura, también actualizada por las nuevas tecnologías, hasta el punto de que se puede hablar de una escritura secundaria ${ }^{2}$, se acerca a modalidades orales que afectan hasta la or-

1 Sanfilippo (2006) lo ha estudiado en su tesis doctoral, comparando lo que ocurre en Italia — donde los lugares preponderantes de la nueva narración son, con mayor frecuencia, los teatros- con lo que sucede en España, donde ésta se desarrolla sobre todo en bibliotecas, como animación a la lectura, o en cafés y lugares minoritarios, entre círculos de lectores-oyentes que se reúnen periódicamente para escuchar historias.

2 Acuño este concepto por analogía con el correspondiente de oralidad secundaria. 
sinúan continuamente en nuestro discurso hablado; de la misma manera, pueden ser objeto de narración incluso las interacciones verbales que nos atañen constantemente. Por ejemplo, contamos a alguien que nos hemos encontrado con otra persona y le hemos dicho «esto y lo otro» (con una fórmula que resume las palabras utilizadas, muy difundida en el italiano hablado y de la que es posible encontrar equivalentes en otros idiomas), refiriendo con amplitud, si se considera oportuno, el tenor de nuestros diálogos y utilizando entonces, para reproducirlos, sobre todo la forma gramatical del discurso directo ${ }^{6}$.

En esta narrativa natural, que aflora continuamente en la producción verbal de cualquier persona, resulta posible distinguir diferentes grados de eficacia o habilidad narrativa en cada hablante: unos son más chispeantes que los demás, saben hacerse escuchar con mayor interés, mientras que otros resultan pedantes y aburridos, incluso cuando cuentan anécdotas que en boca de otros serían divertidas. No todo el mundo posee en la misma medida lo que se puede llamar el arte de narrar. Ello puede depender de varios factores, vinculados a la mayor o menor capacidad de administrar la voz (con sus posibilidades de variación referidas a la entonación, la potencia, el ritmo y la velocidad), la distribución de las informaciones en el texto y la organización general, más o menos fluida, del discurso. Y el de narrar oralmente es un arte que no tiene porqué desarrollarse paralelamente con el arte de escribir cuentos: muchos narradores orales muy hábiles pueden ser casi analfabetos, mientras que existen escritores muy buenos que no saben narrar oralmente $o$ que, cuando lo intentan, consiguen penosos resultados.

$\mathrm{Si}$ además tenemos en cuenta que los factores arriba mencionados son, como sabemos, muy relevantes también para todas las formas teatrales, entendemos inmediatamente la peculiar cercanía que se da entre el cuento oral y el teatro y, en especial, la vocación teatral de los cuentos de tradición oral, en los que puede analizarse la narración como un acontecimiento en la intersección entre cuento y representación, puesto que tienen mucho peso la voz que lo administra y la realización de una especie de puesta en escena del cuento. Aun manteniendo su naturaleza de cuento, el texto asume rasgos marcados de teatralidad: son precisamente los que el teatro acentúa cuando utiliza como fuente los géneros narrativos orales para realizar espectáculos propiamente dichos.

6 Sobre el funcionamiento del discurso reproducido (o cita) en el discurso oral, cf. Mortara Garave1 li (1995b). Para un análisis del fenómeno en distintos tipos de discurso oral, entre los que se da el narrativo, cf. Lavinio (1998). 


\section{GÉNEROS NARRATIVOS ORALES, CONTEXTOS Y GESTUALIDAD}

Los textos que circulan sobre todo, o exclusivamente, en el circuito oral se transmiten de un hablante a otro, en una cadena que ve su continua, y siempre distinta, ejecución. Por lo que concierne a la organización de los contenidos, estos textos están ya preconcebidos, ya listos, pero, cada vez que vuelven a ser contados, es necesario darles una forma expresiva adecuada. Aunque, precisamente, el hecho de que se trata de textos ya presentes en la memoria, con una distribución de los contenidos, en una secuencia ya dada (y, a veces, con segmentos textuales de tipo formulaico ya preparados para ser proferidos y utilizados), aligera notablemente el trabajo de re-producirlos, en una ejecución que es, sin duda, más fluida y segura que la de tipos y géneros de discurso oral menos planificados. Además, la referencia a la tradición, en la que estos textos se sitúan como réplicas, cada vez que se narran, comporta que en ellos recurra con frecuencia un «dice (que)», cuyo sujeto es una voz impersonal e indistinta, equivalente al dicunt latino, de la que es fácil encontrar fórmulas equivalentes en todos los idiomas.

Se trata de textos que se alejan, en muchos aspectos, del discurso oral más espontáneo (el hablado-hablado de tipo conversacional) ${ }^{7}$. Presentan una elaboración formal más marcada, que puede favorecer el empleo de elecciones léxicas y gramaticales ligeramente distintas de las del lenguaje cotidiano. Se trata de textos monológicos (es decir, atribuibles, más allá de su intrínseco y fuerte carácter dialógico ${ }^{8}$, a una instancia enunciativa única), recortados/aislados del continuum de la lengua hablada del que afloran a través de anuncios (como «sabéis la de...»o fórmulas introductorias como el Érase una vez de los cuentos maravillosos) y de cierre.

El género narrativo oral más difundido y practicado en la actualidad, en todos los niveles sociales, es el chiste, que pone en escena un breve episodio en el que, a menudo, dos (o más) hablantes se intercambian frases dialógicas, hasta llegar a la conclusión cómica — la frase graciosa por excelencia-

\footnotetext{
${ }^{7}$ Hagège (1985) ha propuesto el neologismo orature para caracterizar el estilo oral de estos textos, que pertenecen al tipo de discurso hablado que Gregory y Carroll (1978) definen como reciting.

${ }^{8}$ La acepción de carácter dialógico que se trata de evocar aquí es la bachtiniana que considera todo texto, incluso el oral (anclado fuertemente en el contexto y dirigido a destinatarios que, más que en lo escrito, influyen sobre la forma con su estar presentes en el mismo contexto), como un texto que inscribe en su interior a los destinatarios a los que se dirige, haciendo referencia a ellos con el mismo lenguaje y organización textual seleccionados, incluso en ausencia de alocuciones más o menos evidentes.
} 
que, con sus inesperadas desviaciones de sentido, provoca la carcajada. Todos sabemos que no es fácil contar bien un chiste, hasta el punto de que el mismo texto puede alcanzar o no su objetivo cómico según quien lo cuente. ¿Por qué? Evidentemente se trata no sólo de no olvidar los elementos-clave fundamentales del texto, de no alterar el orden de los hechos y las frases (no adelantar nunca, por ejemplo, la frase final), sino de saber manejar el texto con la voz, la entonación, el ritmo, la mímica y la gestualidad adecuadas: nos adentramos ya en las capacidades teatrales que, también de manera innata, algunos hablantes dominan mejor que otros.

Sin embargo, aquí quisiera tener en cuenta sobre todo los géneros de narrativa oral que se definen como tradicionales y populares (es decir, cuentos maravillosos, leyendas, cuentecillos, historias de miedo), historias, cuentos (en el sentido del francés contes o del sardo contus) que forman parte del repertorio narrativo tradicional de una comunidad más o memos amplia, que se contaban en ocasiones y contextos determinados.

Por lo menos en nuestra zona, es decir en Italia y los países europeos, las ocasiones y contextos más conocidos en los que tales cuentos «venían a cuento ${ }^{9}$ seguramente ya han desaparecido (o se han transformado): ya no tienen lugar, por ejemplo, las veglie o los filò, por citar los nombres - utilizados respectivamente en Toscana y en el Norte de Italia - de las reuniones colectivas de una gran familia campesina y/o de vecinos en un lugar amplio, frecuentemente un establo, en el que, mientras los hombres arreglaban los instrumentos de trabajo y las mujeres cosían o tejían, todos se divertían contando o escuchando contar a otros. A veces existían figuras de narradores especializados que iban recorriendo los pueblos para ofrecer sus servicios de entretenimiento; y se trataba de figuras parecidas a las de los griots africanos. En Cerdeña, la gente ya no se congrega en grandes grupos alrededor del hogar (de donde proviene el nombre contos de foghile o de forredda para los cuentos maravillosos), ni en las noches de verano, a charlar y contar cuentos, reunidos los vecinos en calles y plazoletas, en sa friscura (al fresco) o su lugore (a la luz de la luna).

Desde hace tiempo los folcloristas y, en general, los que conservan aún la memorias de tales costumbres subrayan que la desaparición de estas tradiciones está relaciona con la difusión de la televisión, presente en sociedades como la nuestra en todos los hogares, incluso en los centros más aislados y desperdigados.

\footnotetext{
${ }^{9}$ Para este concepto, cf. Milillo (1983).
} 
Sin embargo, eso no quiere decir que también la costumbre de contar historias que pertenecen a géneros tradicionales haya desaparecido por completo. Por ejemplo, según un sondeo llevado a cabo, hace unos años, en Cerdeña, a menudo los viejos siguen contando historias tradicionales en las salas comunes de los hospitales, es decir, en lugares ciertamente inéditos con respecto a la tradición.

Entre otras cosas, ya desde la segunda mitad del siglo XIX, cuando también en Italia se desarrolló notablemente la recolección de cuentos populares, existe la preocupación constante por la desaparición de los textos de tradición oral o la impresión de que están a punto de desaparecer de la memoria colectiva, sin embargo, cada vez que se hacen investigaciones para recuperarlos y grabarlos siempre se encuentra, en las distintas comunidades, alguien que aún los sabe contar.

En otras latitudes, como por ejemplo en los países africanos, los cuentos tradicionales y orales siguen estando muy difundidos e, incluso en las plazas de las grandes ciudades, narradores, por lo general sentados, los ofrecen a los transeúntes en narraciones con mímica. Se trata de fenómenos estudiados detenidamente por Geneviève Calame-Griaule, que ha puesto en evidencia, utilizando una expresión que los mismos narradores informantes le han enseñado, cómo «lo que da sabor a los cuentos» es precisamente la teatralidad que caracteriza su narración: la puesta en escena del cuento, mediante gestos, actitudes, posturas, expresiones del rostro del narrador es como la sal (y el aliño que acompaña a la comida) (Calame-Griaule, 1992). Además, el público oyente forma parte integrante de la totalidad del espectáculo resultante, puesto que, lejos de comportarse con pasividad, coopera con el narrador en la realización del cuento, apreciando determinados puntos en particular e incitando a que el narrador los amplíe y/o vuelva a utilizar en otros momentos los mismos recursos, incluso formales, que han tenido éxito; o incluso manifestando, con preguntas explícitas o interrupciones, la curiosidad que el que narra está obligado a satisfacer, etc.

En la narración oral, la relación entre el que cuenta y el que escucha es tan estrecha que quien llega a dedicarse a los cuentos populares después de tener experiencias teatrales queda fascinado por ella y/o la persigue como modelo. Se puede leer, por ejemplo, el testimonio de Agnes Dumochel, una actriz-narradora que, en el congreso «Passage du conte» ${ }^{10}$, ha tenido la posibilidad de afirmar:

${ }^{10}$ El Bureau Linguistique de Turín organizó este congreso (Augé, Camilleri, Poletti, 1992) en 198990, después de llevar estos problemas a las aulas utilizando las performances de numerosos narradores- 
J'aime aussi cette forme de spectacle, où l' on est bien plus proche du public qu'au théatre, et même à son écoute. On se prive de certains éléments de la magie du théatre. On en gagne d'autres en intimité et en échange. Et quand je conte, j'aimerais comme on dit dans le sud de la France, que ça vous donne envie de le faire aussi. Un conte en appelle un autre, et finalement peut-être plus que toute autre forme de spectacle, les contes invitent à la convivialité (Dumochel, 1992: 28).

Por otra parte, se puede recordar que la forma recurrente, al final de muchos cuentos, de fórmulas como «Dite la vostra che ho detto la mia» no es más que una invitación a narrar dirigida a los demás, a los que idealmente se cede el turno de la palabra narrativa.

Ya en el siglo XIX los investigadores de textos tradicionales percibieron cómo el cuerpo del narrador, con todas sus posibilidades comunicativas y expresivas, entra en juego de forma notable para ofrecer una especie de dramatización-teatralización de lo narrado. Sus trabajos están cuajados de notas sobre la importancia del gesto que acompaña a la palabra, dando precisión o enriqueciendo su sentido ${ }^{11}$. No obstante, es necesario también tener en cuenta que estas prácticas gestuales-teatrales en el curso de una narración están sometidas a variaciones culturales más o menos notables. De una cultura a otra, se puede identificar un empleo distinto y más o menos marcado de los gestos: por ejemplo, en Cerdeña, éstos son mucho más sobrios y contenidos, como resulta también de la investigación y las grabaciones de vídeo realizadas por Pierpaolo Piludu en Scano-Montiferro, con ocasión de la elaboración de su trabajo de fin de carrera (cf. ahora Piludu, 1999). Tenemos conocimiento de que, en algunas culturas orientales, hay que reducir a cero los ges-

\footnotetext{
actores profesionales. Ha representado un momento importante de reflexión sobre las operaciones típicas de ese sector teatral, a menudo dialectal, que investiga y propone, en toda Europa, la identidad de las culturas regionales o subregionales. Se trata de un sector al que pertenecen muchos grupos teatrales activos en las últimas décadas; de hecho basta con una rápida búsqueda en Internet, utilizando palabras clave como teatro y cuento popular o dialectal, para encontrar inmediatamente un gran número de páginas web que ofrecen información sobre un sinfín de iniciativas de este tipo, entre las que operaciones filológicas de recuperación se alternan o coexisten con operaciones, igualmente legítimas, que manipulan y transforman los cuentos tradicionales.

${ }^{11}$ También en épocas más cercanas a nosotros, podemos encontrar testimonios de la importancia de los elementos teatrales en sentido lato que acompañan a la narración, de una importancia de la que son conscientes los mismos informantes populares. En sus investigaciones sobre la narrativa toscana, Paola Tabet, por ejemplo, ha recopilado testimonios de este tipo: «Raccontavano da ridere e novelle lunghe con tutti i versi [...] con le mani [...] con la bocca [...] coi ginocchi»; « e come le raccontavano! Con tutte le mosse; parevano vere» (Tabet, 1978: 71-72). Para más citas sobre este argumento y también para muchas consideraciones presentadas en este trabajo, cf. Lavinio (1993).
} 
tos, mientras que lo que cuenta es la voz, puesto que el narrador tiene que narrar tumbado y con los ojos cerrados, sumido en una especie de trance.

En general, sabemos perfectamente que los gestos (no sólo los que acompañan a los cuentos) están organizados culturalmente: el mismo gesto puede tener un significado distinto en una cultura o en otra. Uno de los ejemplos más conocidos es el del movimiento de la cabeza de abajo hacia arriba (y viceversa), que para nosotros significa asentimiento, mientras que en otras culturas (la griega, sin ir muy lejos) expresa negación. Además, la dosis de gestos que acompaña a la lengua hablada puede ser más o menos relevante, puede comportar continuos tocamientos al interlocutor (como en algunas culturas del sur de Italia) o puede ser mucho más contenida y controlada, en una comunicación que comporta una proxémica muy distinta, con una mayor distancia física entre los interlocutores.

La gestualidad con la que también los nuevos narradores acompañan sus performances merecería, pues, ser considerada atentamente en relación con las palabras pronunciadas, puesto que se trata de un componente importante e imprescindible del texto producido. Sin embargo, en este estudio, podemos limitarnos a recordar su relevancia y, en cambio, dirigir nuestra atención, sobre todo, hacia el componente verbal de los textos orales de tipo tradicional.

\section{TEATRALIDAD LINGÜÍSTICO-VERBAL}

La gestualidad, la mímica, los movimientos corporales en general, pueden ser sólo el aspecto más llamativo de la dramatización inherente a toda narración oral, que, de todas formas, incluso en el caso en que la gestualidad se acerca al grado cero o es mínima, puede contar siempre con los recursos teatrales de la voz, de los que ya hemos hablado. Sin embargo, incluso el aspecto meramente lingüístico-verbal de los cuentos orales muestra un alto porcentaje de teatralidad y está estrechamente vinculado con el contexto en el que se desarrolla, como, por otra parte, sucede con cualquier forma de lengua hablada.

Forman parte del contexto los propios oyentes, que están implicados continuamente a través de preguntas sobre el desarrollo del cuento (por ejemplo «¿entonces qué hace? ¿qué iba a hacer? ¿qué va a pasar?), atraídos hacia un mecanismo de suspense con variaciones del ritmo, cautivos, a veces, dentro del cuento con su nombre o con sus características físicas atribuidas a algún personaje, encantados por la frecuencia de ideófonos (ej.: «iZas!) y ex- 
clamaciones con las que el narrador puntúa la narración. Los oyentes tienen a su vez la posibilidad de tomar parte, además de con (esporádicas) preguntas explícitas, con una actitud de interés y manifestaciones de ánimo (atención, exclamaciones, aplausos, etc.) que incitan a que el narrador subraye de forma histriónica algunos pasajes, los amplíe o los repita cuando resultan especialmente eficaces, o a que, en otros casos, pase por encima y los resuma.

El texto resulta repetido pero también renovado, de forma siempre distinta, así como son distintos los contextos y los oyentes cada vez que incluso el mismo narrador vuelve a contar la misma historia. La estética de la repetición domina toda la narración oral tradicional ${ }^{12}$. A menudo, hallamos en la coherencia textual repeticiones de palabras (como el típico cammina cammina), fórmulas, episodios, triplicaciones, etc. Las repeticiones y la redundancia que, por lo general, son características de la lengua hablada, adquieren categoría de rasgo estilístico caracterizador.

Los cuentos orales tradicionales suelen estar marcados y señalados como narrativos a través de las fórmulas de apertura y las secuencias introductorias, que construyen la situación inicial y proporcionan informaciones básicas, sobre el punto de partida de la historia con una secuencia más o menos extensa de tiempos verbales en imperfecto. Sin embargo, inmediatamente después se introduce el empleo del presente, por supuesto no de una forma sistemática, en la que este tiempo tiende a imponerse con respecto a los tiempos normales del pasado. El presente enmarca y acompaña sobre todo a las partes de diálogo, es decir, a las secuencias que la terminología narratológica define como escenas, con un término que, en sí mismo, recuerda y subraya su teatralidad intrínseca y que indica todos los fragmentos textuales en los que el tiempo de la narración coincide tendencialmente con el del enunciado. De hecho, el tiempo que tardan los hechos narrados en desarrollarse dentro de la historia coincide con el tiempo que se usa realmente para contarlos (en el discurso ${ }^{13}$ ) y permitir que quien escucha los conozca.

Especialmente en estos pasajes, el oyente se halla en una posición similar a la de un espectador que, en el teatro, cuando asiste a los diálogos de los personajes, se encuentra directamente ante la acción escénica, actualizada ante sus ojos. En los cuentos orales, esta actualización destaca desde el mo-

12 Partiendo de la repetición (incluso variada) que coincide con el gusto por la re-realización/ re-escucha de la misma historia, que el público tradicional conoce y controla, ejerciendo respecto al narrador un tipo de censura preventiva, como observaron en un importante estudio Bogatyrëv y Jakobson (1929).

${ }^{13}$ La oposición entre historia y discurso se usa aquí en sentido técnico-narratológico. 
mento en que aparece el presente entre los tiempos verbales. Y se trata de presentes que podemos definir como escénicos (en lugar de históricos), que tienden hacia una mayor densidad después de un elemento introductorio como hete aquí: en otras palabras, en una secuencia que se abre con un «hete aquí (que)», el empleo del presente de indicativo representa la norma. Aparece también en secuencias que empiezan con indicaciones temporales precisas (un día, una mañana, etc.). Se introducen de esta forma acontecimientos que adquieren relevancia con respecto a la repetitividad de una situación-marco, más descrita que narrada (como la inicial, desde la que se desarrolla la historia), en la que el tiempo verbal típico es el imperfecto. En los cuentos orales, el uso del presente no es — por supuesto — plano y sistemático y se alterna con tiempos más propiamente narrativos, incluido el indefinido $^{14}$; en cambio, la aparición y frecuencia relativa de los presentes escénicos que aparecen en textos escritos puede considerarse como un primer parámetro que delata en ellos una cierta tasa de oralidad.

En concomitancia, el ritmo del cuento (en el sentido narratológico de resultado de la relación entre la duración de la historia y la duración del discurso) se vuelve más lento y aparece el diálogo, en el que verba dicendi poco variados introducen o puntean las frases: decir es, con diferencia, el más frecuente, utilizado de forma casi exclusiva ${ }^{15}$. Por otra parte, en los cuentos orales no falta casi nunca el discurso directo que constituye la modalidad sobresaliente para la reproducción de la palabra dicha en comparación con el discurso indirecto, que, en cambio, en muchos casos brilla por su ausencia. En muchos casos el diálogo ocupa un espacio textual mucho más relevante en comparación con el que ocupa la palabra del narrador. En resumidas cuentas, para ser más exacta, es corriente que la mímesis sea más extensa que la diégesis, y con frecuencia es posible hallar cuentos orales en los que las frases de diálogo ocupan un espacio tan amplio que las anotaciones narrativas introductorias o intercaladas acaban por desempeñar el papel de simples y sobrias acotaciones.

Además, dentro de las mismas acotaciones, es decir, en las partes en las que el narrador no presta su voz a los distintos personajes, dejando que ha-

${ }^{14}$ Incluso en textos escritos es obvio que pueden aparecer escenas con este tipo de presente, cuya frecuencia puede ser tomada como parámetro revelador de una determinada tasa de oralidad propia o de adopción de modalidades orales en la escritura. Hecho cada vez más frecuente en la narrativa contemporánea en la que se va reduciendo la separación entre lo hablado y lo escrito.

15 En la forma hablada en italiano se puede encontrar una forma tan genérica como hacer con el sentido de decir (ej.: «e mi fa: - Perché non mi hai chiamato?-»). 
blen directamente, aparecen muchos deícticos que remiten a la situación de la enunciación narrativa, al contexto en el que se está produciendo el cuento. Pero el ambiente, el contexto que comparten narrador y oyentes, a su vez, puede transformarse en un auténtico espacio escénico, trasladado y reconstruido, como espacio, dentro de la ficción para ser el telón de fondo de los acontecimientos narrados. Es posible comprobarlo, por ejemplo, en un cuento recopilado por Vittorio Imbriani, en el que la narradora, para sugerir el lugar en el que se desarrolla la acción narrada, dice «ma qui, dichiamo, questa fosse la camera; e qui, dichiamo, ci fosse le guardie» (Imbriani, 1877: 173) ${ }^{16}$.

En este contexto ambivalente, es decir, real pero utilizado también para construir el espacio del cuento, como ya se ha dicho, se busca continuamente el contacto con el público, a través de preguntas que intentan implicarlo en la espera del desarrollo de los hechos narrados y a través de otros numerosos fatismos (o fórmulas de contacto) de distinto tipo; en cambio, por otra parte, no faltan pasajes explicativos (desde formas aparentemente irrelevantes, como las interjecciones hasta secuencias más explícitas y más o menos extensas) con los que el narrador, haciendo referencia a una moral y un sistema de valores que comparte con su público, expresa juicios sobre los hechos narrados.

Ejemplos de todo esto podrían extraerse fácilmente de textos populares recopilados en épocas y lugares distintos (siempre que hayan sido transcritos de forma suficientemente fiel), pero se trata ya de fenómenos muy conocidos y estudiados.

\section{PARA UN PRIMER SONDEO}

Teniendo en cuenta lo dicho, se puede sacar de ello una primera plantilla útil para analizar los textos que los nuevos narradores orales producen en sus performances. Está claro que, por lo general, no se trata de textos tradicionales. Frecuentemente son reelaboraciones de la memoria ${ }^{17}$, de fragmentos de historias de vida, enfocados hacia episodios y personajes presentados

16 Imbriani trabajaba en época premagnetofónica, pero siendo sensible a la necesidad de reproducir lo más fielmente posible el dictado popular, solía taquigrafiar los textos que iba recogiendo de la boca de sus informantes, a menudo analfabetos. En el fragmento citado es mi cursiva la que pone de manifiesto los deícticos.

${ }^{17}$ No es casualmente por lo que este Teatro de Narración es designado también a menudo como Teatro de la memoria. 
como reales. Pero también se trata de tener en cuenta que las modalidades usuales en los cuentos orales tradicionales pueden haber representado el modelo para la evolución y la construcción de las historias de vida, como vienen subrayando desde hace tiempo los estudiosos de la historia oral.

Por lo tanto, comparando entre ellos textos producidos por narradores distintos, se puede prestar atención a la presencia, ausencia y frecuencia relativa

a) de alocuciones a los destinatarios, que pueden consistir incluso en el simple recurso a una segunda persona, singular o plural, además de las preguntas ya mencionadas o en muletillas de otro tipo;

b) de referencias de todo tipo al contexto, bien como situación espaciotemporalmente determinada en la que la narración se desarrolla y a la que remiten los deícticos, bien como contexto cultural más amplio (con comentarios que remiten a una cultura más o menos compartida y en los que se expresa una especie de juicio del narrador con respecto a los hechos narrados);

c) de interjecciones e ideófonos que, como se ha dicho, salpican frecuentemente, y con extraordinaria eficacia, el habla narrativa;

d) de formulaciones como «dice (que)», que caracterizan el texto como reproducido desde la voz de otras personas;

e) de escenas dialogadas, que prestan atención también al tipo de verba dicendi que acompañan a las frases en discurso directo, introduciéndolas o intercalándolas;

f) de empleo del presente escénico para que la narración avance;

g) de partes de cuento repetitivo ${ }^{18}$, en las que se cuenta varias veces, casi con las mismas palabras, lo que en el eje de la historia (o fábula) ha tenido lugar una sola vez.

Por otra parte, se trata de caracteres de tipo supralingüístico, que aparecen en las producciones narrativas orales (y tradicionales) de distintos idiomas y que, por lo tanto, pueden ser aceptados como útiles por encima del hecho de que el análisis y los ejemplos se refieran a textos italianos.

${ }^{18}$ En la acepción narratológica de Genette (1972). 
Es evidente que la consideración de tales caracteres puede ir acompañada por notas relacionadas con la correspondiente modificación de la voz del narrador (su velocidad) y de la postura, mímica o gesticulación.

Un trabajo sistemático sobre estos aspectos comporta grabaciones en vídeo, continuas escuchas y/o transcripciones de performances reales, que además nunca son, obviamente, idénticas, ni siquiera cuando se trata de ejecuciones del mismo texto por parte del mismo narrador ${ }^{19}$. Se trata de un trabajo largo y paciente, que se desarrolla a través de comparaciones minuciosas entre distintas performances y/o con respecto a posibles redacciones escritas de los mismos textos y/o, cuando son localizables, con las fuentes con las que están relacionadas (ej.: testimonios orales grabados de la boca de varios informantes).

En este trabajo se procede únicamente a una rápida exposición de los resultados de un primer sondeo, llevado a cabo teniendo en cuenta los puntos arriba indicados y realizado sobre algunas grabaciones de vídeo elegidas de forma totalmente casual.

\subsection{Scemo di Guerra, de Ascanio Celestini}

La grabación del espectáculo de Celestini está en un DVD, publicado, junto con el texto escrito (Scemo di guerra. Il diario. 2006-1944), por Einaudi en 2006. En el libro hay una primera parte de diario, en la que, a través de anotaciones fechadas (van desde el 30 de junio de 2005 hasta el 11 de enero de 2006), Celestini habla de su trabajo, empezando a desvelar su génesis y el método utilizado. Sigue la parte de las Memorie, de Sisto (Il rastrellamento del Quadraro) y de Nino (La liberazione di Roma), respectivamente, construidas intercalando las palabras del autor (en cursiva) con las de sus informantes. Celestini enlaza y comenta, resumiéndolas y en parte repitiéndolas o completando las informaciones, las palabras (en redonda) de los dos, que presentan sus propios recuerdos personales de la vida cotidiana en una Roma asolada por los bombardeos (obviamente estamos a finales de la segunda guerra mundial), por los rastreos (que llevarán a Sisto a Alemania), e incluso por la misma liberación de los americanos. Aflora una gran riqueza de anécdotas y una multitud de personajes. Son sobre todo chiquillos (y

${ }^{19}$ O narrattore, como alguien ha propuesto denominar a estos nuevos narradores que, a menudo, son también narrautori, que acumulan sobre sí mismos las funciones de autor, narrador, actor e incluso director del espectáculo que se pone en escena, en sitios convencionales ( como en el teatro) o fuera. 
sus parientes y conocidos) del popular barrio romano del Quadraro, pero también soldados anónimos, alemanes o americanos. Son los personajes que Celestini pone después en escena y los transfigura, en clave surrealista, en su cuento-espectáculo.

A parte del espectáculo, el DVD también reproduce fragmentos grabados directamente de la boca de Sisto Quadraro y Nino Celestini, el padre del autor. De esta forma, vemos y escuchamos a Sisto que cuenta; en cambio sólo se oye la voz de Nino, mientras que en la pantalla aparecen fotos de familia de la época.

Incluso un primer examen somero de este material permite ver cómo, en el pasaje de la palabra de los informantes a su escritura (aunque presentada como trascripción), muchas cosas cambian y se transforman, llegando al final, en el espectáculo, a un resultado muy distinto que, aunque se basa en esos textos (dichos y escritos ${ }^{20}$ ), transforma ambos, reelaborándolos, en una operación realizada muy conscientemente ${ }^{21}$, que acentúa algunos de sus aspectos y prescinde de otros ${ }^{22}$. Paradójicamente se llega a resultados mucho

${ }^{20}$ Sería mejor decir grabados (en la memoria), a través de escuchas reiteradas, después repetidos en boca de Celestini y, en determinado momento, como en el caso de Scemo di guerra, consolidados también por escrito (para la publicación del libro), pero sin pretender, en esta redacción escrita, cristalizarlos/fijarlos en una forma que las interpretaciones orales posteriores tengan que respetar. Cf. lo que ha afirmado el mismo Celestini a propósito del método utilizado en la reelaboración de los cuentos orales recogidos: «L'ascolto delle storie è già rielaborazione [...] Nei miei spettacoli non c'è mai un lavoro di scrittura» (G. Pettiti, s.d.).

${ }^{21}$ Conviene recordar que Ascanio Celestini es un narrador culto que, en la Facultad de Letras de La Sapienza de Roma ha entrado en contacto con todos los problemas referentes al teatro de la memoria, a partir de un enfoque antropológico y etnográfico, reforzado por su relación con Alessandro Portelli, famoso experto en narración y en historias de vida orales y con Mario Martone, apasionado director de espectáculos en los que la memoria se convierte en teatro. De hecho uno de los primeros trabajos de Celestini fue Cecafumo (publicado por Donzelli en 2002, con CD incluido), que contiene la narración/reelaboración de cuentos populares tradicionales (leyendas, cuentos, historietas con Giufà como protagonista) dentro de un continuo proceso de «fragmentación y desfragmentación» para el que Celestini ha seguido «le dinamiche sottese al racconto orale, al ritmo del discorso, che va ben al di là dell'intreccio narrativo e si avvicina invece alle regole della composizione musicale, con i suoi temi, le sue ripetizioni e le sue varianti» (Reddavide, 2005).

${ }^{22}$ En particular, ya en la transcripción, incluso en los puntos en los que aparece más fiel a la grabación de las declaraciones/testimonios de Sisto y Nino, se constata la omisión de las repeticiones locales de palabras, sílabas (ej.: «mia madre alle ... alle quattr'e mezza del mattino proprio all'albeggiare ... all' albeggiare» dice Sisto. Uso los puntos suspensivos para señalar breves pausas) o los lapsus (ej.: «le galline di Sirio», dice Sisto, para corregirse inmediatamente después: « di di Silvio»). Como resulta fisiológico en la lengua hablada, se trata de simples fenómenos de incertidumbre y/o respiración en la ejecución, relacionados con el trabajo de tener que escoger (tomándose el tiempo necesario para encontrarlas) y disponer las palabras una tras otra en la composición oral del texto. Después, en el texto del espectáculo, las repeticiones de este tipo vuelven a aparecer, pero de forma muy casual y esporádica (ej.: «in lontananza se se vedevano certi soldati»). 
más miméticos con respecto a algunos de los caracteres más relevantes de los cuentos orales tradicionales, en relación con la huella de tales caracteres difundidos en el habla narrativa de los informantes.

Pero en este trabajo nos vamos a limitar al texto del espectáculo, que dura en total una hora y treinta y siete minutos (incluida la reproducción audio del final, en la que oímos directamente la voz de Nino). Celestini, en cuanto entra en escena (un simple biombo y una silla) empieza a contar, sin fórmula introductoria alguna: «Mio padre era il secondo di quattro fratelli». En el nombre del padre empieza el espectáculo que después, como ya se ha recordado, se concluye con su misma voz grabada, confirmando casi la circularidad, repetitiva e infinita, de una historia que podría continuar durante largo rato y que acaba por reproducir la repetitividad de las innumerables veces en las que la misma historia ha sido narrada por el padre, durante casi treinta años y casi con las mismas palabras, como si las hubiera escrito.

La gestualidad de Celestini es eficaz pero sobria, con un movimiento de las manos para acompañar el sentido de las palabras o para mimar, a veces, algunas de las acciones narradas (como cuando sugiere el movimiento de aplastar unos piñones con el fondo de un vaso). Y sobra decir cuánto contribuye también a imprimir ritmo al texto ${ }^{23}$.

El diálogo con el público y las alocuciones dirigidas a él son muy contenidas: se circunscriben a algunos fatismos como no? capito? a algún figuriamoci en el que el narrador también implica a los destinatarios gracias a la primera persona del plural. Sin embargo, las referencias al contexto en el que la narración se desarrolla y del que forma parte el mismo yo del narrador se condensan en el Epilogo (así aparece en el DVD, que divide en secuencias, con diferentes títulos, el cuento ininterrumpido de Celestini). Aquí Celestini afianza de forma metatextual la veracidad de su cuento y, al mismo tiempo, la operación creativa a la que ésta ha sido sometida («Questa storia è quella che mio padre ha raccontato tutta la vita, non proprio così come l'ho raccontata io... io mi sono inventato un sacco di cose [...] la mosca che parla per esempio me la sono inventata io»), subrayando también su propio «divagare» antes de retomar el hilo de la historia ${ }^{24}$; cuenta que, el día de la muerte del

\footnotetext{
23 A veces, aflora bien un sobrio acompañamiento musical (fragmentos de G. Verdi y de E. Pancaldi), bien otros sonidos (ej.: el canto de los grillos en el episodio nocturno en la orilla del río). Alguna vez Celestini, que en general suele narrar sentado, narra de pie, como en el caso en el que, abriendo los brazos, sugiere la calma chicha del agua del río, inmóvil en la noche como el agua en un vaso.

${ }^{24}$ En todo el relato, han aflorado numerosas divagaciones y digresiones, como la que se refiere a la inteligencia de los monos o la de la dificultad de la desinsectación. Además, dentro de estas digresiones, han aflorado otras historias, como la de la Virgen y las moscas, con cierto sabor a leyenda.
} 
padre, él llegó de Milán «con 'sto vestito addosso» (y se toca, enseñándola, la chaqueta que lleva en el escenario), vuelve a tratar uno por uno los temas y los distintos personajes del cuento ${ }^{25}$ (la sociedad del cerdo, el tonto de la guerra, el barbero de manos bonitas, el perro, el chaval paraculo, la Sora Irma, el cine Iris, el padre) y repite sintéticamente la historia de cada uno, pero también, como en los epílogos dignos de este nombre, da informaciones que llegan a menudo hasta el presente y la actualidad (ej.: «la Sora Irma, la trattoria della sora Irma, quella che stava attaccata al cinema Iris [...] è rimasta trattoria ancora oggi solo che è ristorante cinese, trattoria cinese, diciamo»), con comentarios que pueden ser compartidos o verificados por el público.

Además, en todo el texto, aparece sistemática y continuamente, aunque con picos de frecuencia en algunos puntos, la fórmula dice che: la historia narrada se afianza, como tomada nuevamente de voces, que a veces se pueden identificar - las de Sisto y del padre - y otras son más genéricas e indeterminadas. La narración es en todo momento un cruce polifónico de mil voces distintas, bien anónimas o que se pueden adscribir con toda seguridad a los distintos personajes. El autor reproduce sus frases preferentemente en discurso directo ${ }^{26}$, pero sin énfasis ni cambios bruscos de voz y tono. Para marcarlas son suficientes los numerosos disse (o diceva) que, sin variaciones por lo que atañe a la selección léxica, las introducen o intercalan ${ }^{27}$. También en este aspecto es visible una rígida adherencia a las reglas generales de la reproducción de lo dicho en la lengua hablada; mientras que, en el texto escrito, algunos de los análogos disse de los cuentos orales de Sisto (o de Nino) han sido sustituidos, en cambio, por verbos más exactos, con una extensión semántica menor (ej.: cominciò a urlare, rispose).

En la performance narrativa de Celestini llama la atención el uso sistemático del pretérito indefinido como tiempo verbal que hace avanzar la na-

25 Aparecen construcciones sintácticas de tema libre o sospeso y dislocaciones a la izquierda, típicas de la lengua hablada. Desde el punto de vista de la organización textual, es especialmente evidente un ritmo en el que el tema, colocado en primera posición, casi como un anuncio o un título, se desarrolla después en un fragmento más o menos amplio.

${ }^{26}$ Aunque no faltan puntos en los que la palabra de los personajes se reproduce en forma indirecta, como en el caso de las conversaciones mantenidas en el restaurante de la Sora Irma, sobre la necesidad de apartar un poco de dinero («lire mille») para comprar el cerdo que un primo suyo ha robado a los alemanes (la «società del maiale») en Frascati.

${ }^{27} \mathrm{Ej} .:$ «A giudicare da com'erano vestiti questi soldati pareva che erano americani. Infatti qualcuno lo disse: —Oh! vedrai che mo' so' arrivati l'americani. Finalmente so' arrivati. — No — qualcun altro invece disse — guarda che secondo me so' ancora i tedeschi- Qualcuno invece, per mettere d'accordo tutti, disse: - Mah! secondo me so' tedeschi travestiti da americani» (la transcripción es mía y he introducido la puntuación que me ha parecido más adecuada, para facilitar la lectura de la cita). 
rración, incluso en determinadas escenas dialogadas ${ }^{28}$ (marcadas por disse y no por dice). Por supuesto, el indefinido es también el tiempo fundamental que utiliza Sisto, mientras que en el habla de Nino parece dominante el pretérito perfecto; sin embargo, por lo menos alguna vez, en sus narraciones aflora el tiempo presente. El uso del indefinido en Celestini resulta, por lo tanto, más bien distanciador y distanciado, un uso que, además, contribuye a aumentar la sensación de enorme velocidad con la que se desarrolla la narración, con un efluvio o cúmulo de palabras que, de golpe, puede parecer incluso difícil de seguir. La velocidad de su discurso también se puede poner en relación con el dialecto romano que 'le da color' y que implica frecuentes recortes de palabras con respecto a la forma italiana standard (aféresis como en 'sto en lugar de questo; truncamientos como en anda' por andare, vede por vedere, mi' por mio etc.), con una drástica reducción de su importancia fónica (a menudo los artículos y las preposiciones se reducen a un único sonido consonántico poco perceptible) y también del tiempo de pronunciación. Sin embargo, también el habla de Nino es en dialecto romanesco muy marcado y sus tiempos más distendidos (se pueden medir comparando, por ejemplo, el número de palabras que pronuncia en un minuto con las que utiliza, en cambio, su hijo en el espectáculo), que resultan evidentes en una primera impresión meramente auditiva.

Incluso las inevitables interjecciones que aparecen a veces entre las palabras del narrador (en la diégesis) son escasas en número y tipología (ej.: $V a$ $b e$ ! Eh!, Bah). Aparecen también algunos ideófonos, concentrados en el punto en el que Celestini quiere reproducir con varios $b l . . . b l \ldots$ el ruido del cerdo y con frink frunk frank el sonido de las palabras del soldado alemán que habla en su idioma. Tampoco falta, a lo largo de la narración, la aparición de un cammina cammina (y también de un camminando camminando), es decir, de la fórmula más adecuada para ampliar el espacio recorrido y el tiempo utilizado para recorrerlo. Se trata de una fórmula ya establecida por la repetición estilizada de la misma palabra. Pero Celestini recurre a la reiteración también en otros casos: para crear el elativo utiliza siempre la repetición del mismo adjetivo (ej.: l'uomo dal «braccio lungo lungo secco secco») y son incontables las veces en las que los mismos adjetivos caracterizadores acom-

${ }^{28}$ Para mayor claridad, se puede subrayar que se hace referencia, obviamente, sólo a la diégesis, excluyendo tanto los insertos comentativos en los que pueden aparecer presentes deícticos que se refieren a la situación de la enunciación narrativa, como las frases de diálogo (mímesis), en las que, cuando son los personajes los que hablan, es inevitable que aparezcan presentes que también tienen valor deíctico, pero que se refieren al contexto (narrativo) en el que aflora su palabra. 
pañan, casi como si fueran fórmulas, el retorno a la escena narrativa de los mismos personajes (ej.: il ragazzino paraculo, il barbiere dalle mani belle). En un nivel más general, el cuento es frecuentemente repetitivo (los mismos episodios se narran varias veces, de una forma aparentemente idéntica, que sólo la trascripción puede revelar como ligeramente distinta), con una circularidad y un ritmo que a menudo se abren sobre una dimensión surrealista, pasando a veces por una nueva propuesta de modalidades que recuerdan a los cuentos de fórmula. Véase, en particular, el episodio del barbero de las manos bonitas que se dirige hacia el río para enterrar al perro al que ha disparado y entonces un hombre lo detiene para cargarlo con el cadáver del padre. Después, una mujer le pide que dé sepultura al marido (y le da un carro en el que cargar los cadáveres); después, otra vez, una pareja le confía el cadáver de su niño. Todas las veces, se dirigen al barbero con la misma expresión («dove andate ...») y todas las veces su respuesta se alarga, repitiendo todo lo que uno detrás de otro, sus interlocutores le han ido exponiendo para convencerlo de que se hiciera cargo de otro cadáver más. Al final los muertos que hay que llevar al río son muchísimos («lo fermò tutto il paese») y, después de que el barbero se hiciera el muerto entre los muertos, primero con la llegada de los americanos y después de los alemanes, resucita y hace que todos esos muertos resuciten, incluido el perro.

Por lo tanto, incluso sin tener en cuenta la magia especial de ese episodio $^{29}$, se puede concluir diciendo que el carácter que más y mejor acerca el cuento de Celestini a la tipología de la narrativa oral tradicional es su intensa y rítmica repetitividad.

\subsection{L'asso dell'aviazione, de Davide Enia}

La grabación en vídeo de esta performance narrativa, que dura 30 minutos, procede de una trasmisión del programa televisivo Report, transmitida por RAI3 el 10 de septiembre de 2004. Por lo tanto el público está formado por teleespectadores y no por un público en el plató en el momento de la transmisión.

${ }^{29}$ Piénsese también en la magia vinculada, en otros casos, a la presencia de animales que piensan y hablan. Por lo que se refiere a la acumulación y a los crescendo, véase además el episodio de la especie de procesión que se crea detrás de la carretilla del muchacho paraculo y sus patatas. Hay un viejo que parece mudo (y que después, en cambio, hablará «come l'oracolo», con un grupo de enunciados que se abre sistemáticamente con una insistente anáfora: «A casa mia...»), pero se añaden también, uno tras otro, «mi' nonno, mi' padre, il barbiere, il cane». 
Nos encontramos en Palermo en abril de 1943; por lo tanto, como en Scemo di guerra de Celestini, en la época de la segunda guerra mundial ${ }^{30}$. Pero Enia construye su monólogo como si el que hablara fuera Giachino, un chiquillo que precisamente el día anterior ha cumplido doce años. Giachino es el narrador propuesto por el texto y en el texto, en el que el narrador real Enia delega la tarea de construir el cuento, dirigiéndose desde el incipit («Ciao Rosario, fratello mio») a un interlocutor también fictivo. Rosario es el hermano muerto de Giachino, que el chiquillo ha ido a visitar al cementerio. Por lo tanto, el largo monólogo de Giachino se desarrolla sobre su tumba y dice que le ha traído un regalo y le cuenta la partida de cartas, que ha tenido lugar, el día anterior, entre el tío Baldo y un americano, que se han apostado un secreto militar. El tío ha ganado haciendo trampa.

Durante el desarrollo de la partida estaban presentes cinco personas en total. Se introducen fragmentos sobre la guerra y los bombardeos, contando con cinco ciegos, que incluso oyen mejor que los que ven, a los que han llevado a una azotea para que espíen la llegada de los cazabombarderos. Se evocan sirenas y carreras hacia los refugios, mapas militares y calendarios de guerra que tienen como objetivo, entre otras cosas, asolar Palermo... La narración se desliza desde una dimensión aparentemente cómica a otra vagamente surrealista, simplemente sugerida, con algunas digresiones, como en el caso de los ciegos que piensan en el color del sol y el color del mar.

Enia, sentado en una silla, a lo largo de la narración se levanta y sube a la silla o se sienta en el respaldo. El texto resulta dramatizado de una forma muy marcada por lo que se refiere a la gestualidad y también a los cambios de voz (desde el murmullo hasta casi el grito) en relación con lo que dicen (siempre en estilo directo) los personajes a los que el narrador presta su voz: se trata de un decir a veces lloroso, a veces airado, a veces calmado, a veces enfadado. El ritmo varía muy notablemente, volviéndose extremadamente rápido en algunos momentos, más lento y distendido en otros, con pausas incluso muy largas. Con respecto al estilo sobrio y esencial de Celestini, Enia pone un notable énfasis de conjunto en la actuación; es un autoractor que con seguridad escribe antes sus propios textos y que ha tenido ocasión de afirmar que las palabras «devono essere spese da un corpo sulla scena, e sono altresì parole che hanno l'urgenza di farlo vivere quel corpo, fino a modificare gesti e toni di chi quel personaggio incarna» (Cicerone,

${ }^{30}$ Davide Enia ha realizado ya, por otra parte, el espectáculo narrativo Maggio '43, construido sobre recuerdos familiares contemplados con la mirada de un niño de doce años. 
2004). Por lo tanto, el cuerpo y la voz están presentes antes y en mayor medida que en Celestini.

Aunque Enia niega haber estudiado la narración oral tradicional ${ }^{31}$, vemos que también en su caso aparecen muchos de sus caracteres más típicos, incluso considerando sólo la parte verbal de su narración teatral. Y entendemos que no es casual que Enia pueda ser definido como un cantastorie redivivo, aunque, en la narración tradicional, no se da el caso de un narrador que renuncie a su propio yo para asumir la identidad de un narrador distinto de sí mismo, como, en cambio, hace este artista.

No faltan los ideófonos como ese tippete tappete tu para llamar a la puerta del piso donde se va a desarrollar la partida o como los sonidos producidos para mimar el ruido de los cazabombarderos o las bombas ${ }^{32}$. Constantemente aflora una densa narración dialogada, cuyas frases, a menudo, no están marcadas por ningún verbum dicendi, puesto que, para separarlas de la diégesis, es suficiente el paralelo y marcado cambio de voz, entonación e incluso el cambio de idioma del narrador (ej.: «e da dentro si sente: - Who are you? Chiste come parla? - Sta' calmo, Giachino. E' americano. Siamo qua per giocare la partita a carte - . La porta si apre». Sólo lo que se oye aclara que hay que atribuir a Giachino la frase «Chiste come parla?», mientras su tío le contesta, para después dirigirse, desde «Siamo qua» a quien está dentro de la casa). Si en la diégesis encontramos un italiano sicilianizado, cuando hablan el tío Cesare o el tío Baldo aflora de forma todavía más nítida el dialecto siciliano $^{33}$. Pero encontramos además el inglés de los dos americanos, repro-

31 Véanse por ejemplo, además de las distintas entrevistas legibles en su página web (www.davide enia.org), las respuestas al cuestionario presentado por Sanfilippo (2006), en el CD que acompaña al trabajo. Enia reconoce de todas maneras su deuda con Dario Fo (especialmente con el Fo de Mistero buffo, citado a menudo como modelo por los distintos 'nuevos narradores') o con la narrativa teatral de Marco Paolini (cf. Soriani, 2005).

${ }^{32}$ La sensibilidad por la reproducción fónica de los sonidos y ruidos puede haber ido madurando en Enia a través de su pasión por el cómic. Además aparece por un lado y por otro, incluso el acompañamiento de una guitarra o de un percusionista, que, de forma muy discreta, subrayan icónicamente todo lo que han ido evocando las palabras y el relato.

33 Incluso la gestualidad que acompaña el decir puesto en escena está regionalmente - y conscientemente (Soriani, 2005) — bien caracterizada: "la mia gestualità deriva proprio dal dialetto: Napoli e Palermo sono le uniche città in cui il gesto è parte integrante del discorso", ha declarado Enia (en Soriani, 2005). Pero no se puede estar completamente de acuerdo con su afirmación: más allá del recurso, notoriamente más marcado, a la gestualidad en el sur de Italia, se puede decir que siempre y en todo lugar el gesto es parte integrante, junto a otros componentes sígnicos, de la textualidad oral. Cirese (1991: 10) ha hablado también de su multiplicidad de planos o multidimensionalidad haciendo alusión a la concurrencia de signos pertenecientes a códigos diferentes — "fónico-auditivos" y "visivo-gestuales (mímica, cinética y análogos)" - utilizados de forma simultánea en la "producción oral de un texto verbal". 
ducido, sin embargo, con una entonación y modalidades articulatorias evidente e intencionadamente sicilianas (además, también en la ficción de la narración, lo reproduce un chiquillo siciliano), mientras que, cuando Enia hace que hablen en italiano, se imita y marca su acento anglo-americano.

La mímesis lingüística de la lengua hablada real es completa, incluyendo la reproducción del típico fenómeno de foderato (con la repetición de la misma palabra al principio y al final de un enunciado, como en $«$ Prego Giachino, prego $»^{34}$ ). En el narrador Giachino, encontramos la acostumbrada repetición de palabras con función de intensificación semántica (ej.: la expresión scurosa scurosa, seria seria» del tío Cesare), la repetición rítmica de enunciados calificativos (ej.: en distintos puntos se repite que el tío Baldo «è zuoppo con la moglie scricchiata»), la hábil creación de contrastes, como el delicioso contraste entre el americano rubio y el tío Baldo, construido sobre tres oposiciones paralelas ${ }^{35}$, que alguien cierra siempre riendo; lo que sucede es que quien ríe el último, con una repentina inversión, es el tío Baldo... («L'americano biondo è ricco, pieno pieno di piccioli. Lo zio Baldo invece è com'a noaltri, un morto di fame. E chisto l'americano lo sa e ride. L'americano è elegantissimo in uniforme, come l'autro americano. Lo zio Baldo invece è zuoppo con la moglie scricchiata e ci have pure i toppe in d'o culo. $\mathrm{E}$ questo l'americano lo sa e ride. L'americano è un ufficiale dell'esercito americano, ci ha i gradi sulla spalla, ci ha. Lo zio Baldo invece è un baro di carte. E chisto l'americano non lo sa e lo zio Baldo ride»).

Sin embargo falta el relato repetitivo y la narración de los hechos avanza de forma más bien lineal, aunque existen por lo menos dos relatos en el cuento que retroceden en el tiempo con respecto a los acontecimientos del día de la partida de cartas. Para que la narración avance, en la diégesis se utilizan sistemáticamente los tiempos del presente: se trata de un presente especial y evidentemente escénico, que acentúa la toma directa sobre todos los hechos narrados y mimados por el narrador.

Su declarado centro deíctico ${ }^{36}$ es el tres de abril de 1943, desde el que Giachino cuenta el día anterior («tutto comincia ieri 2 aprile 1943, il mio compleanno») y también lo que había pasado «due mesi fa» (es decir «il primo febbraio 1943»), con los fascistas que llevan a los ciegos a las azoteas de

\footnotetext{
34 Pero incluso el Giachino narrador habla de esa manera (ej.: "E vince lo zio Baldo, vince").

35 Siempre subrayadas por la voz y las pausas de las que la puntuación, introducida en mi transcripción, sólo puede dar una idea muy aproximada.

${ }^{36}$ En la acepción ampliamente estudiada por Mortara Garavelli (1985 y 1995a).
} 
los edificios, o también «una settimana fa esattamente da oggi», cuando ha llegado un mapa con los escondites de los cazas americanos que, en África, han bombardeado un hangar de cartón piedra... Y las modalidades de la narración permiten ver sin esfuerzo escenas y ambientes que, por otra parte, ya gozan también de una extensa tradición de representación cinematográfica, más allá de la visión de las cartas marcadas, con dos ases de corazones, que aparecen realmente en la mano de Enia-Giachino al cerrarse el espectáculo.

\subsection{Las historias de Claudio Zanotto Contino (La Ballata di Gelsomina)}

El vídeo La Ballata di Gelsomina es una producción de la Regione Piemonte y el Museo Nazionale della Montagna «Duca degli Abruzzi» de Turín, dirigida en 2001 por Vittoria Castagneto. En la película vemos a Claudio Zanotto que, de pie entre un público sentado en semicírculo ante él, cuenta dos breves historias; pero éstas están integradas en un vídeo lleno sobre todo de composiciones musicales y vistas sugestivas — a veces paisajes de montaña, otras de playa - que sirven de fondo al recorrido del propio Zanotto y la mula que lo acompaña (Gelsomina, que, de hecho, es casi una presencia actoral de apoyo) en busca de historias para contar. Mientras pasan las imágenes, una voz femenina habla de la importancia de recoger y sembrar las historias, en un movimiento que nunca tiene fin, como el de las olas: las historias son como «i passaggi, i corridoi che ti portano da una stanza all'altra» y sin los cuentos «il mondo si ferma, la vita muore». Estas sugestivas declaraciones de poética corresponden a la operación que Zanotto lleva adelante desde hace por lo menos una década, es decir, desde que, obligado por una hernia a estar inmóvil, leyó con mucho interés una recopilación de cuentos y leyendas tradicionales de su región (Crema, 2005). Y se ha convertido en narrador de cuentos. Si, a menudo, sus fuentes son escritas, quizá lo sea aún más su forma de contar (basada en una palabra escrita y estandard), que aparece como la repetición oral de un texto escrito aprendido de memoria: si quien escucha no viera que el narrador no está leyendo, podría de hecho pensar lo contrario.

La misma trascripción de sus palabras, pronunciadas con voz lenta y más bien monótona, resulta más sencilla que en el caso de los demás narradores estudiados hasta ahora. Y es suficiente con introducir la puntuación para obtener un texto bastante estandard, que carece de todos los fenómenos, incluso sintácticos, que caracterizan a la lengua hablada y que convierten en difícil o en no inmediata la transposición/legibilidad de lo escrito. 
Ambas historias, la del hombre que tenía prisa (y que después, gracias a un urcià, «signore dei boschi», o meglio «delle caverne che stanno dentro ai boschi», aprendió a ir despacio) y la de los barcos en el fondo del Lago Verde (una leyenda), se abren con C'era una volta, la fórmula de apertura percibida como la más normal para las historias tradicionales que reciben una redacción escrita $^{37}$. El primer cuento se cierra con un igualmente canónico «da allora visse felice e contento»; el segundo con una explicación al público (en segunda persona plural): «Ancora oggi quando passate vicino al Lago Verde e sentite delle voci o dei fischi, ricordatevi: non sono gli animali, ma i marinai che rispondono agli ordini del grande ammiraglio Garanta». Los tiempos de la narración están todos en pasado, existe únicamente (y sólo en el primero de los dos cuentos) una frase en estilo directo, marcada por un diceva pospuesto («Voi qui siete tutti indietro, diceva»); faltan interjecciones e ideófonos, la repeticiones se limitan a alguna iteración léxica (ej.: «lo fece andare piano piano piano»). Aunque la sintaxis es simple y paratáctica, no faltan construcciones que hacen pensar en una sintaxis escrita (véase, por ejemplo, este largo periodo que se abre con una frase circunstancial con gerundio: «Non bastandogli gli uomini, le macchine, i cannoni, gli uccelli di fuoco, chissà quali altre diavolerie, Garanta chiamò le navi e le lanciò all'attacco»). Y se utiliza un italiano que carece de matices regionales, aunque aparece (en el primer cuento) un término local en piamontés (l'urcià), explicado de inmediato.

Entre otras cosas, para comprobar la gran distancia entre las narraciones de Zanotto y las orales, bastaría con compararlas con el cuento en dialecto piamontés que, en la película, le cuenta un viejo. Sin embargo a Claudio Zanotto, evidentemente, sólo le interesan los acontecimientos, es decir, el contenido de las historias más que la forma de la narración. Como por otra parte, ha pasado repetidamente en la misma historia de las investigaciones folclóricas.

\subsection{En síntesis}

Para concluir estas anotaciones, se puede subrayar, resumiendo, hasta qué punto los tres narradores difieren, en primer lugar, por la velocidad del habla, que es máxima en Celestini, aunque con mínimas variaciones internas; mucho más variada en Enia, con aceleraciones y reducciones hasta pausas cional.

37 Mucho más variadas pueden ser, en cambio, las fórmulas de apertura de la narrativa oral tradi- 
largas y silencios; de lentitud más bien uniforme en Zanotto. Para dar mejor razón he contado el número de palabras (incluidas preposiciones y artículos) presentes en el minuto y cuarenta segundos que dura, aproximadamente, la primera historia narrada por Zanotto. Suman 133 palabras en total. Contando las primeras 133 palabras del incipit de Scemo di guerra, en el que, por otra parte, Celestini parece menos rápido que en otros puntos de su texto, se descubre que las pronuncia en 38 segundos, es decir, en un tiempo más de dos tercios menor.

A la gestualidad, expresiva pero contenida, de Celestini, se opone la de Enia, mucho más marcada, mientras que Zanotto posee una gestualidad poco expresiva y más bien convencional.

Por lo que se refiere a los otros parámetros estudiados, se puede visualizar su presencia o ausencia en cada uno de los trabajos analizados, a través de una tabla que, sin embargo, no indica su frecuencia relativa.

\begin{tabular}{|l|c|c|c|}
\hline & Celestini & Enia & Zanotto \\
alocuciones al público & + & - & + \\
otras referencias deícticas al contexto & + & - & - \\
interjecciones e ideófonos & + & + & - \\
presencia de «dice che» & + & + & \\
presencia de escenas dialogadas & + & + & - \\
verba dicendi (dire) & + & $+/$ & + \\
presente escénico & - & + & - \\
cuento repetitivo & + & - & - \\
italiano regional o dialectal & + & + & - \\
\hline
\end{tabular}

En Enia encontramos una ausencia general de referencias al contexto (real) aunque, obviamente, están presentes las que se refieren al contexto construido por el cuento (de Giachino que narra), mientras que el verbo dire para marcar el discurso citado (en la forma de estilo directo) a menudo está ausente, como ya se ha dicho, o alterna a veces con gridare (a eso se refiere el $+/-$ de la tabla para este punto).

Por lo que respecta a Zanotto, a pesar de que en sus textos se halla una frase en discurso reproducido en forma directa, no se ha considerado suficiente, por su aislamiento y su aparición esporádica, para constituir una escena dialogada (por lo que se ha insertado un signo para tal punto). 
Además, resulta inútil insistir en la importancia de la presencia de un tipo de lengua connotada geográficamente o salpicada por elementos dialectales más o menos evidentes: en un país como Italia, la lengua hablada real y, sobre todo, popular nunca está libre de matices locales. Y el vínculo con la realidad, a parte de la tradición, pasa también a través de elecciones lingüísticas que no sean asépticas, sino que consigan la resonancia de esta o esa habla local, de esta o esa variante que la variedad del repertorio lingüístico italiano ofrece a sus hablantes.

Incluso desde el punto de vista visual, la tabla muestra, quizá más y mejor de lo que se ha dicho hasta ahora, una mayor proximidad de Celestini a las modalidades lingüísticas y textuales características de los cuentos orales tradicionales.

Sin embargo, constatar todo esto no tiene la pretensión de establecer como juicio de valor una mayor proximidad al modelo tradicional. En cambio, se trata más bien de poner de manifiesto la utilidad de una reflexión sobre los fenómenos arriba explicados, con la convicción de que las operaciones del que quiera revitalizar la narración popular, en cualquier caso, tienen que llevarse a cabo de una forma consciente, bien porque se quiera respetar filológicamente las reglas, ya teatrales, de la narración oral, bien porque se quiera modificarlas, quizá para adaptar al teatro de forma más marcada textos que se inspiran o quieren inspirarse en la memoria popular.

\section{REFERENCIAS BIBLIOGRÁFICAS}

Augé, G. et alii (eds.) (1992). Passage du conte. Torino: Tirrenia Stampatori.

BogatiReV V, P. y JaKobSOn, R. [1929] (1967). «Il folklore come forma di creazione autonoma». Strumenti Critici 3, 223-238.

Calame-Griaule, G. (1992). «Ce qui donne du goût aux contes». En Augé et alii (1992), 1-18.

Cicerone, F. (2004). «Davide Enia tra memoria e racconto per non dimenticare». Rivista Prometheus IV, 84 [entrevista a D. Enia que se puede leer también en www.davideenia.org].

Cirese, A. M. (1991). «Introduzione». En Da spazi e tempi lontani. La fiaba nelle tradizioni etniche, D. Conci (ed.), 7-20. Napoli: Guida.

CORTI, M. (1982). «Nozione e funzioni dell'oralità nel sistema letterario». En Oralità e scrittura nel sistema letterario (Atti del Convegno di Cagliari, 
14-16 aprile 1980), G. Cerina, C. Lavinio, L. Mulas (eds.), 7-21. Roma: Bulzoni.

CREMA, G. (2005), «Quell'attrice è un'asina. Geraldina va in scena». $L a$ Repubblica, 3 agosto.

Dumouchel, A. (1992). «Le conte est un objet magique». En Augé et alii (1992), 27-28.

GenetTe, G. [1972] (1976). Figure III. Discorso del racconto. Einaudi: Torino.

Gregory, M. y CARroll, S. (1978). Language and Situation. London: Routledge \& Kegan Paul.

Hagège, C. (1985). L' homme de paroles. Paris: Librairie A. Fayard.

IMBRIANI, V. [1877] (1976). La novellaja fiorentina con la novellaja milanese. Milano: Rizzoli.

LAVINIO, C. (1993). La magia della fiaba tra oralità e scrittura. Firenze: La Nuova Italia.

- (1998). «Tipi di parlato e discorso riportato». En Italica Matritensia. Atti del Convegno SILFI (Madrid, 27-29 giugno 1996), M. T. Navarro Salazar (ed.), 299-313. Firenze: Franco Cesati Editore.

Milillo, A. (1983). La vita e il suo racconto. Roma-Reggio Calabria: Casa del Libro.

Mortara Garavelli, B. (1985). La parola d'altri. Palermo: Sellerio.

- (1995a). «Il discorso riportato». En Grande grammatica italiana di consultazione, vol. III, L. Renzi, G. Salvi, A. Cardinaletti (eds.), 427-468. Bologna: Il Mulino.

- (1995b). «Il discorso diretto nell'italiano parlato». En La subordination dans les langues romanes, H.L. Andersen y G. Skytte (eds.), 69-88. Copenaghen: Université de Copenaghen.

Ong, W. (1982). Orality and Literacy. The Technologizing of the Word. London and New York: Methuen.

Pettiti, G. (s.f..). «Intervista ad Ascanio Celestini». En www.frameonline.it.

Piludu, P. (1999). Posidos. Cagliari: Condaghes.

Pistolesi, E. (2004). Il parlar spedito. L'italiano di chat, e-mail e SMS. Padova: Esedra editrice. 
Reddavide, G. (2005). Reseña a Cecafumo di A. Celestini. En www.studiantropologico.it.

SANFILIPPO, M. (2006). El renacimiento de la narración oral en Italia y España (1985-2005). Tesis doctoral defendida en la UNED (que puede leerse en «Estudios sobre Teatro», en la página electrónica $h t t p: / / w w w$. uned.es/centro-investigacion-SELITEN@T).

SORIANI, S. (2005). «Tradire la tradizione. Conversazione con Davide Enia». Laboratorio del segnalibro, 28 dic. (se puede leer en www.davideenia. org).

TABET, P. (1978). C'era una volta: Rimosso e immaginario in una comunità dell' Appennino toscano. Rimini-Firenze: Guaraldi. 


\section{LOS CAMINOS DEL TEATRO NARRAZIONE ENTRE ESCRITURA ORALIZANTE Y ORALIDAD-QUE-SE-CONVIERTE-EN-TEXTO}

\section{Gerardo GUCCINI}

Universidad de Bologna guccini@muspe.unibo.it

Resumen: En este trabajo se estudia el fenómeno del Teatro Narrazione en Italia, reconstruyendo su evolución histórica y analizando las prácticas compositivas de sus intérpretes principales.

Abstract: In this work I study the phenomenom of the Teatro Narrazione in Italy by recalling its historical evolution and analysing its main interpreters' practices.

Palabras clave: Narración. Oralidad. Actor. Teatro. Drama

Key words: Narrative. Orality. Actor. Theatre. Drama. 
ganización del texto, aparte de la lengua utilizada, muy espontánea, planificada sólo en una mínima parte, a causa de la naturaleza de los intercambios que ocurren en tiempo real, sin que se prevea una recepción aplazada (baste pensar en las chat), o que están condicionados por el exiguo espacio del que se dispone (como en los SMS, que incitan a braquilogías y grafías ${ }^{3}$ que, al ser trasladadas a textos de otro tipo, a pesar de que son muestra de una auténtica dejadez, se van difundiendo cada vez más) ${ }^{4}$.

Volviendo a la narrativa y en particular al fenómeno de los nuevos narradores, ¿se trata de una reactivación y de una nueva difusión de la primitiva modalidad del cuento ${ }^{5}$, que ha sobrevivido largo tiempo, en los circuitos de la tradición oral y popular tradicionales, a pesar de la presencia de la escritura? En cierto sentido sí, pero, sin duda, pasando por una cultura, colectiva cuando no individual, impregnada de escritura.

Por lo tanto, para entender y evaluar las características de las nuevas narraciones, puede ser útil recordar cuáles son los rasgos, incluso lingüísticos, característicos de la lengua hablada y de la narrativa natural que en ella se desarrolla, y sobre todo los característicos de la narrativa oral tradicional. Este conjunto de rasgos puede servir como metro para medir la mayor o menor distancia entre los nuevos narradores y los tradicionales y puede permitir identificar los distintos estilos de cada narrador, vinculados precisamente al empleo peculiar o la frecuencia, presencia o ausencia de estos rasgos típicos, a veces acompañados por otros más propios de la escritura que de la lengua hablada.

\section{VOCACIÓN TEATRAL DEL CUENTO ORAL}

De forma preliminar, se puede recordar la enorme capacidad de difusión del narrar: fragmentos narrativos, relacionados con uno de los miles de episodios de la vida cotidiana que nos ve como protagonistas o testigos, se in-

\footnotetext{
${ }^{3}$ Por ejemplo: $C$ 6? por $C i$ sei?; xiodo por periodo, etc. Pero ahora ya, incluso en la elaboración de textos que tendrían que ser más esmerados (desde trabajos de clase a tesis doctorales), el recurso a los signos de operaciones de aritmética elemental (no sólo x, sino +, -) está ampliamente documentado, como también $k$ en lugar del nexo gráfico $c h$ (ej.: ke per che).

4 Son fenómenos que se empiezan a estudiar ampliamente. Para el italiano cf. por ejemplo Pistolesi (2004).

${ }^{5}$ Quizá no sea inútil, aunque resulte obvio, recordar que en la historia de la humanidad, habiendo lenguas que se han desarrollado y vivido mucho tiempo sin escritura, también los cuentos y el arte verbal en general se han practicado originalmente de forma oral.
} 